
PORTO ALEGRE: DA IDEOLOGIA PARTIDÁRIA À EFICIÊNCIA MIDIÁTICA

\author{
VOTER AND ELECTORAL COMMUNICATION IN PORTO ALEGRE: FROM \\ PARTY IDEOLOGY TO MEDIA EFFICIENCY \\ ELECTOR Y COMUNICACIÓN ELECTORAL EN PORTO ALEGRE: DE LA \\ IDEOLOGÍA PARTIDISTA A LA EFICIENCIA MEDIÁTICA \\ Carla Mendonça ${ }^{1}$ \\ Jéssica Duarte 2
}

RESUMO: este artigo apresenta uma análise das eleições municipais de 2008, 2012 e 2016 em Porto Alegre, capital do estado do Rio Grande do Sul (RS), Brasil, a partir da construção de um quadro comparativo entre o comportamento dos eleitores e as estratégias de comunicação das coligações. São analisadas características históricas do eleitorado, resultados eleitorais e estratégias de comunicação eleitoral, e, finalmente, são comparados os dados dos candidatos vitoriosos nos três pleitos. Busca-se identificar os modelos mais bem-sucedidos de comunicação eleitoral nesses pleitos e se há padrão histórico de comunicação eleitoral que leve os candidatos ao poder ou se novas estratégias vêm sendo agregadas aos processos. Identificamos a repetição de temas, abordagens e uso de mídias nos dois primeiros pleitos, com inflexão na última eleição, a de 2016.

Palavras-chave: Comunicação Política. Campanha Eleitoral. Comportamento Político.

ABSTRACT: this article analyses the 2008, 2012 and 2016 local elections in Porto Alegre, the capital of the state of Rio Grande do Sul (RS), Brazil, based on the building of a comparative framework between voter behaviour and political coalitions' communication

\footnotetext{
ORCID: 0000-0002-9899-9638 - E-mail: cetiene@gmail.com

2 ORCID: 0000-0003-1903-6559-E-mail: jeh.sduarte@gmail.com
} 
strategies. Electorate historical features, electoral results and electoral communication strategies are analysed and, finally, the data of the winning candidates in the three ballots are compared. The aim is to identify the most successful models of electoral communication in those elections and whether there is a historical pattern of electoral communication that leads candidates to power or whether new strategies are being added to the process. We identified themes, approaches and media use repetition in the first two ballots, with inflection in the last one, in 2016.

Keywords: Political Communication. Electoral Campaign. Political Behaviour.

RESUMEN: este artículo presenta un análisis de las elecciones municipales de 2008, 2012 y 2016 en Porto Alegre, capital del estado de Rio Grande do Sul (RS), Brasil, a partir de la construcción de un cuadro comparativo entre el comportamiento de los votantes y las estrategias de comunicación de las coaliciones partidistas. Se analizan las características históricas del electorado, los resultados electorales y las estrategias de comunicación electoral, y finalmente se comparan los datos de los candidatos ganadores en las tres papeletas. El objetivo es identificar los modelos más exitosos de comunicación electoral en estas elecciones y si existe un patrón histórico de comunicación electoral que lleve a los candidatos al poder o si se están agregando nuevas estrategias a lo proceso. Identificamos la repetición de temas, enfoques y uso de los medios de comunicación en las dos primeras elecciones, con inflexión en la última elección, en 2016.

Palabras clave: Comunicación Política. Campañas Electorales. Comportamiento Político.

\section{Eleitor e comunicação eleitoral em Porto Alegre: da ideologia partidária à eficiência midiática}

Este artigo apresenta uma análise das eleições municipais de Porto Alegre, capital do estado do Rio Grande do Sul (RS), Brasil, na última década, a partir da construção de um quadro comparativo entre o comportamento dos eleitores e as estratégias de comunicação das coligações para identificar os modelos mais bem-sucedidos de comunicação eleitoral nesses pleitos.

Nos últimos 50 anos as campanhas eleitorais têm mudado muito, mas a partir dos anos 90 a inovação tem sido cada vez mais célere, fruto do processo de globalização e modernização, do jornalismo crítico, do desenvolvimento tecnológico dos media e da elevada concorrência entre os partidos políticos que apostam continuamente em novas estratégias de marketing (ESPÍRITO SANTO; FIGUEIRAS, 2010, p. 77). 
O marketing político tem suas origens nos Estados Unidos. Lá, conforme Espírito Santo e Figueiras (2010), a maioria dos cargos públicos é alcançada por eleição, a legislação eleitoral é pouco restritiva, os partidos políticos têm componente ideológico reduzido quando comparado aos europeus, por exemplo, e o eleitorado tem um comportamento volátil e pragmático, orientado para questões conjunturais.

No entanto, campanhas eleitorais por todo o planeta têm seguido o caminho do marketing político crescentemente. Interpretações de senso comum veem esse fenômeno como um "sinal de americanização da política" (ESPÍRITO SANTO; FIGUEIRAS, 2010, p. 77). Entretanto, são os processos de globalização e modernização produzindo transformações políticas e midiáticas pelo globo que se refletem também nas estratégias de comunicação eleitoral - neste trabalho, preferimos o termo comunicação eleitoral a marketing político.

As autoras salientam que sistema político, sistema eleitoral, cultura política e estrutura de mídia em cada país são especificidades fundamentais para se compreender o papel da comunicação eleitoral e suas estratégias em períodos de campanha política. Entre os aspectos de contextualização da análise da comunicação política, elas destacam:

[...] o espaço público e a opinião pública; o poder político e o regime; a globalização, internacionalização da política e da comunicação; os movimentos sociais, os grupos de interesse e os grupos de pressão; os meios de comunicação social, a agenda pública e as técnicas de construção; divulgação e noticiabilidade da mensagem política; os novos espaços públicos; o comportamento eleitoral e a participação política; o mercado e a campanha eleitoral; as técnicas de investigação social, como os inquéritos e sondagens de opinião" (ESPÍRITO SANTO; FIGUEIRAS, 2010, p. 81).

Desde a modernização do processo eleitoral, a identificação do público de interesse em campanhas eleitorais - os eleitores - é o passo fundamental para a definição da estratégia de comunicação. Ela é importante para pelos menos dois pontos chaves: a personalização da campanha e o uso estratégico da mídia. Figueiredo (1994) destaca ainda a utilização de pesquisas sociais na identificação dos públicos como ferramenta importante para a definição da estratégia de comunicação eleitoral. Costa (2013) argumenta que atualmente não se faz mais campanhas sem o apoio de pesquisas que ofereçam a caracterização do perfil dos cidadãos. A compreensão do contexto social, além do político, é passo básico para a vitória. 
No entanto, obviamente, o pleito vai além da pré-campanha, e a disputa pode ser dividida em diferentes etapas e eventos que exigem uma revisão das análises e estratégias feitas inicialmente. Marenco (2009) afirma que os cenários de primeiro e segundo turno, por exemplo, podem ser absolutamente distintos.

Considerando os aspectos de contextualização da análise da comunicação política propostos por Espírito Santo e Figueiras (2010), neste estudo, focamos na agenda pública e nas técnicas de construção, na campanha eleitoral e no comportamento eleitoral para compreendermos o que ocorreu em Porto Alegre nos períodos analisados.

Para compreender porque as campanhas dos vitoriosos foram bem-sucedidas, analisamos os resultados eleitorais no município nesses períodos, os quais indicam quais argumentos e instrumentos de estratégia de comunicação política tiveram melhor efeito perante o eleitorado. Com a comparação esperamos verificar se há algum padrão histórico de comunicação eleitoral que leve os candidatos ao poder.

Para isso, cruzamos elementos da comunicação eleitoral dos candidatos de 2008, 2012 e 2016 com os resultados dos pleitos, o que permitiu identificar perfis comportamentais do eleitorado porto-alegrense e quais os discursos e estratégias de comunicação conquistaram maior adesão deles.

Com essa análise, queremos compreender quais foram os melhores mecanismos de comunicação utilizados nas campanhas dos candidatos que melhor aderiram às características comportamentais do público eleitor na cidade.

\section{Revisão de literatura}

A análise das características comportamentais dos votantes em um processo eleitoral é indispensável porque o sucesso de qualquer planejamento em comunicação requer a identificação do público de interesse, os stakeholders; no caso de campanhas eleitorais, os eleitores (LLOYD, 2005).

Manin (1995) e Norris (2000) dividem a democracia em três etapas com base na relação e nas formas de comunicação entre políticos e eleitores: a democracia parlamentar, definida pelas relações pessoais; a democracia de partido, marcada fortemente pelo associativismo, militância e posicionamentos partidários; e, por fim, a democracia de público, caracterizada pelo enfraquecimento dos partidos e reforço da imagem individual do candidato e pelo crescimento do papel da mídia de massa no processo. Esse último estágio resulta na substituição da ideologia e das grandes bandeiras por posicionamentos menos demarcados e, fundamentalmente, pelas técnicas de marketing e usos da mídia de massa (SWANSON, 1995). 
Os discursos políticos vêm sendo crescentemente adaptados para o formato que melhor se adapta a essa última etapa, aquele que consegue maior adesão na mídia de massa - jornal, rádio e televisão. Ele é marcado pela emissão de mensagens diretas, claras, curtas e pessoais, baseadas em planos concretos e na negação de construções abstratas (SWANSON, 1995). Como consequência, ocorre o esvaziamento de conteúdos ideológicos e a substituição dos perfis político-partidários pelos profissionais-técnicos. A assessoria de marketing político torna-se mais fundamental do que a militância. A mídia torna-se o principal campo de disputa eleitoral, e, portanto, monitorar o público e os principais mecanismos de acesso a ele é uma chave para a vitória nas urnas.

O surgimento e a evolução, nas últimas três décadas, dos novos meios de comunicação digital levam o processo para além da mídia de massas (GIDDENS, 1990; HOWARD, 2006). Essas novas ferramentas, em especial as redes sociais digitais, não precisam da intermediação jornalística da informação e possibilitam a interatividade (CANAVILHAS, 2009). Contudo, essa aproximação entre público e candidatos não necessariamente traz consigo engajamento em relação a conteúdos políticos ou ideológicos de fato. Castells (1996) afirma que, nas ligações em rede, as informações circulam de forma mais fluida e direta, com feedbacks mais objetivos.

Pesquisadores da comunicação política e eleitoral vem se dedicando a compreender e salientar a importância desse último aspecto. Serrano (2010) identifica que é progressivo o uso de redes sociais pelos políticos para se pronunciarem e repassarem as informações diretamente aos cidadãos e eleitores, em especial o Twitter e o Facebook.

Conforme Kerbel (1998), as duas grandes vantagens desses novos meios de comunicação são a escala e a proximidade, ou seja, eles permitem codificar a mensagem nos mais diversos formatos com interatividade em amplitude global. Ferreira (2011) argumenta que as ferramentas da internet, geralmente, não têm poder para mudar votos que já estejam consolidados, mas são capazes de influenciar fortemente o eleitorado indeciso ou menos posicionado.

Figueiredo (1994) destaca, entretanto, que cada formato e meio de comunicação possui características próprias e que as peças de comunicação devem ser construídas de forma coerente para o meio em que será inserida - se para jornal, rádio, televisão ou internet - e para o perfil de cada veículo de cada meio. Além disso, como salienta Norris (2000), as transformações nas formas de comunicação entre candidatos e eleitores durante a disputa eleitoral não são lineares e pode ocorrer retorno a características de campanhas pré-modernas mesmo em tempos pós-modernos. 
O processo de disputa eleitoral e a comunicação de campanha envolvem uma quantidade complexa de fatores que vêm se transformando ao longo do tempo. Contudo, é constante que as formas e instrumentos de troca de informações entre candidatos e eleitores são ponto chave.

A partir dessas observações acerca do processo democrático eleitoral e do funcionamento dos mecanismos de comunicação política que o envolvem, cabe examinar o perfil histórico do eleitor porto-alegrense.

\section{A cultura e o comportamento político do porto-alegrense}

Dias, Noll e Krause (2011) afirmam que a análise das campanhas eleitorais é fundamental para compreender o processo de tomada de decisão do eleitor porto-alegrense. Os autores citam uma pesquisa realizada pelo Núcleo de Estudos sobre Poder, Partidos e Eleições, da Pontifícia Universidade Católica do Rio Grande do Sul (PUCRS), que indicava que, em 2004, o Horário Gratuito de Propaganda Eleitoral (HGPE) 3 em rádio e televisão era "importante" ou "muito importante" para 60\% do eleitorado e, portanto, incidia na decisão do voto.

A literatura indica que a crença nas estruturas partidárias, no papel central do Estado como articulador de políticas públicas e nos modelos associativistas são importantes na história do RS e do município de Porto Alegre (TRINDADE, NOLL, 1991; BAQUERO, 1995; MARENCO, 2009). Outro fator determinante na formação desse quadro político é o papel da constante "guerra de braço" entre os partidos associados às ideias trabalhistas e os das frentes que se opunham a esse perfil ideológico (TRINDADE, 1975).

Compartilhando esse ponto de vista, Marenco (2009) discute a importância do voto retrospectivo para o eleitorado gaúcho e as raízes históricas da identidade trabalhista e antitrabalhista no estado. Essa dinâmica teve papel marcante em quase todas as eleições disputadas no município, à exceção, conforme examinaremos com cuidado posteriormente, do pleito de 2016, o qual, apesar de ter o voto retrospectivo levado em consideração na campanha, apresentou características muito mais semelhantes aos estágios atuais da disputa democrática.

A capital gaúcha, em dezembro de 2016, tinha 1.098.258 cidadãos aptos a $\operatorname{votar}$ (TSE, 2018). Em 2010, a população total era de 1.409.351, sendo $54 \%$ do sexo feminino, e a taxa de alfabetização de indivíduos de mais de 10 anos era

3 O Tribunal Regional Eleitoral do Rio Grande do Sul disponibiliza informações sobre os processos eleitorais desde 2008, como pesquisas e propaganda eleitoral, incluindo o HGPE. Disponível em: http://www.tre-rs.jus. br/eleicoes/eleicoes-anteriores/eleicoes-anteriores. Acesso em 20 dez. 2018. 
de $97,8 \%$ (Porto Alegre, 2016). Conforme dados da FEE (2018), em 2015, Porto Alegre tinha um Produto Interno Bruno (PIB) de $R \$ 68,1$ bilhões, o que representava $17,8 \%$ do PIB do estado e colocava o município entre os seis maiores do país. Tinha ainda o maior Valor Adicionado Bruto (VAB) da indústria, com participação de $8,6 \%$ do total estadual, além de $22,9 \%$ de participação no VAB dos serviços.

Esses fatores determinam fortemente as características políticas e eleitorais da cidade. Dentre outras propriedades do perfil social e político de Porto Alegre, é possível destacar: 1) relativa dominância dos partidos de centro-esquerda ao longo do tempo; 2) papel central do ideário trabalhista; 3) associativismo; 4) uma ampla classe média; e 5) altos índices de participação política (MARENCO, 2009). Com efeito, a identificação do público porto-alegrense com os discursos mais relacionados aos temas associativistas ou trabalhistas definiram o cenário das disputas eleitorais durante quase toda a história política do município. $O$ predomínio do trabalhismo em Porto Alegre se fez presente e forte, mantendo o Partido Trabalhista Brasileiro (PTB) como partido hegemônico durante todo o período democrático até o golpe militar, de 1947 a 1964. Com o regime militar e a reforma do sistema partidário instaurada em 1966, a hegemonia do PTB se refletiu na predominância do Movimento Democrático Brasileiro (MDB) no município durante todo o período de ditadura.

Tabela 1 - Eleições para a Câmara de Vereadores de Porto Alegre (\% dos votos)

\begin{tabular}{|c|c|c|c|}
\hline Partido & 1968 & 1972 & 1976 \\
\hline Arena* & 35,81 & 38,81 & 31,15 \\
\hline MDB & 59,19 & 51,09 & 58,20 \\
\hline Brancos & 1,73 & 3,15 & 1,76 \\
\hline Nulos & 3,34 & 6,95 & 3,62 \\
\hline
\end{tabular}

Fonte: Noll e Passos (1996, p. 33). *Aliança Renovadora Nacional

A reforma partidária de 1979 restabelece o pluripartidarismo no país. É então que ocorre a fundação do Partido dos Trabalhadores (PT), o qual passa a ocupar um espaço fértil na capital gaúcha: o do trabalhismo de centro-esquerda. No entanto, no período entre 2000 e 2004 , inicia-se um processo de decadência da preferência do PT pelos eleitores. Marenco (2009) destaca a associação inversa que começa a se estabelecer entre votos no PT e escolaridade média por bairro: 
o aumento da classe média e da escolaridade da população impacta negativamente no desempenho eleitoral do partido.

Além dessa inversão, nas eleições municipais de 2016, o eleitorado porto-alegrense optou por eleger Nelson Marchezan Júnior, do Partido da Social Democracia Brasileira (PSDB), o candidato que, de certo modo, substituiu o discurso trabalhista e associativista tradicional na capital por argumentos voltados à modernização do aparato público e à renovação das estruturas administrativas. Esse fato encontra congruência nas explicações que definem a terceira etapa do processo democrático eleitoral como o momento do afastamento dos partidos e ideologias para enfocar na personalização e na tecnicidade dos candidatos (MANIN, 1995; NORRIS, 2000).

\section{Método}

Neste estudo, reunimos características sociais e históricas do eleitorado de Porto Alegre e identificamos os principais argumentos de comunicação eleitoral dos candidatos nos pleitos municipais de 2008, 2012 e 2016 para depois compararmos as campanhas e os resultados das principais coligações.

Na breve descrição do perfil do eleitorado, analisamos sexo, escolaridade e idade (o recorte etário é de 16 anos, quando o indivíduo se torna apto a votar no Brasil, mesmo que facultativamente até os 18 anos).

Partimos de uma revisão de literatura sobre fatores ou características culturais e históricas no município, analisamos as características próprias de cada disputa e descrevemos os padrões de comportamento eleitoral nos três pleitos para explicar o que influenciou esse comportamento, considerando que esses fatores se relacionam de forma complexa e contínua.

Depois, cruzamos os dados de comportamento eleitoral com os modelos de comunicação eleitoral que conquistaram maior adesão no município. Para isso, analisamos o conteúdo dos discursos dos candidatos, fazendo um levantamento manual dos temas e abordagens mais utilizados na propaganda eleitoral - e nas redes sociais, quando essas foram utilizadas -, e, a partir disso, avaliamos as estratégias de maior sucesso utilizadas por eles nas eleições selecionadas.

Nos processos de 2008 e 2012, televisão, rádio e campanha de rua foram os principais meios de comunicação eleitoral utilizados pelos candidatos vencedores. Em 2016, rádio perde importância, e além de televisão e campanha de rua, entra em cena o uso mais intensivo da internet e das mídias sociais. Isso exigiu a análise desses dois meios, aportando à pesquisa mais dados do que os disponíveis nas duas campanhas anteriores. 
Por fim, comparamos os três pleitos, descrevendo continuidades e descontinuidades nos padrões descritos na literatura, com o fim de compreender a trajetória, as tendências e o status atual da comunicação política do município.

\section{Resultados}

Os gráficos a seguir trazem dados demográficos do eleitorado porto-alegrense nos anos dos pleitos analisados que estão disponíveis no site do Tribunal Superior Eleitoral (TSE)4: 2012 e 2016. O objetivo é completar a identificação do público de interesse, iniciando pelo gráfico de faixa etária:

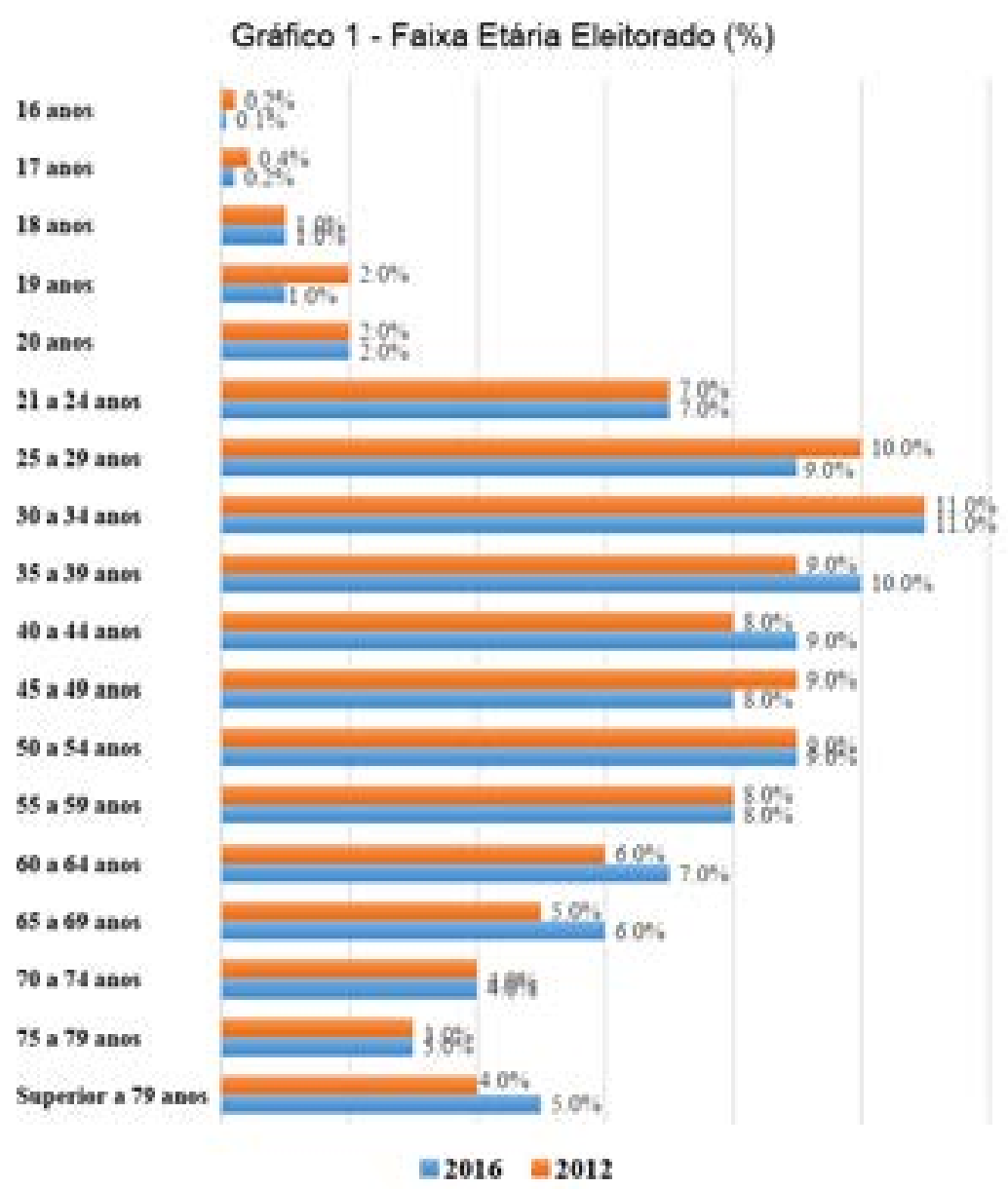

Fonte: TSE - Estatísticas.

Pode-se perceber uma preponderância de eleitores da faixa etária entre 21 e 35 anos, menor presença de pessoas idosas e participação baixíssima de jovens

4 O TSE - Estatísticas. Disponível em: http://www.tre-rs.jus.br/eleicoes/estatisticas/estatisticas. Acesso em: 20 dez. 2018. 
de 20 anos ou menos. Além disso, observa-se uma manutenção dos padrões de frequência para os dois anos apresentados. O eleitorado porto-alegrense concentra-se, fundamentalmente, na faixa etária economicamente ativa.

O Gráfico 2 mostra a distribuição do eleitorado por sexo:

\section{Gráfico 2 - Sexo Eleitorado (\%)}

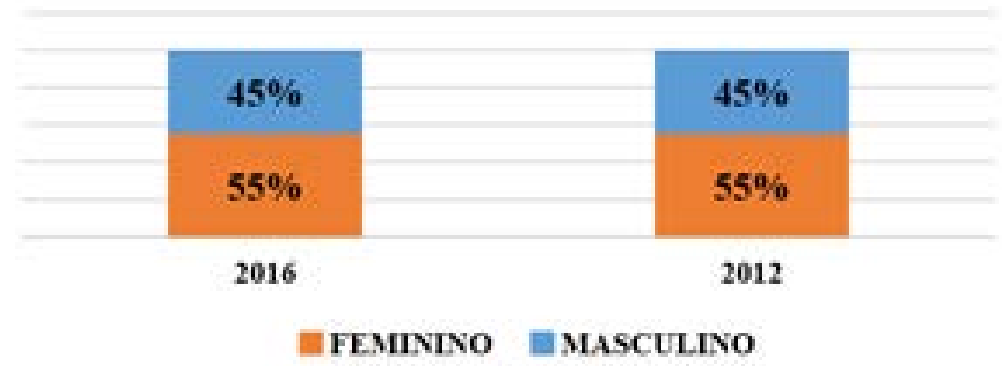

Fonte: TSE - Estatísticas.

O eleitorado se mantém com frequência uniforme para essa categoria nos dois anos, além disso, a proporção segue o padrão nacional de uma maioria feminina em relação aos homens. No Gráfico 3, vê-se a escolaridade dos eleitores:

\section{Gráfico 3 - Escolaridade Eleitorado (\%)}

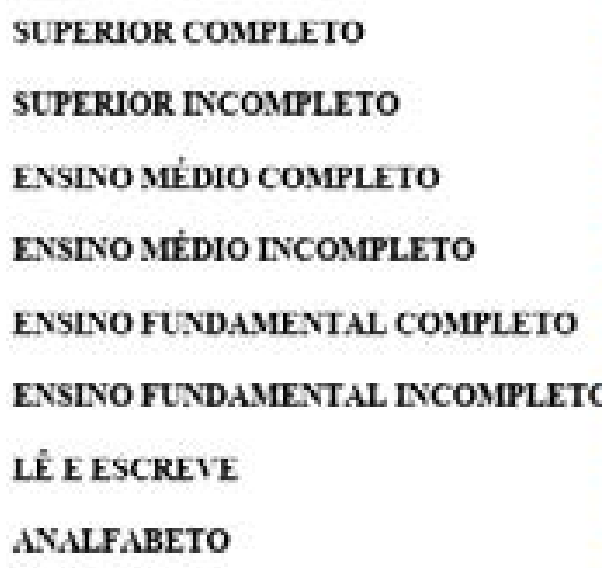

SUPERIOR INCOMPLETO

ENSINO MÉDIO COMPLETO

ENSINO MÉDIO NNCOMPLETO

ENSLNO FUNDAMENTAL COMPLETO

LẾ E ESCREVE

ANALFABETO
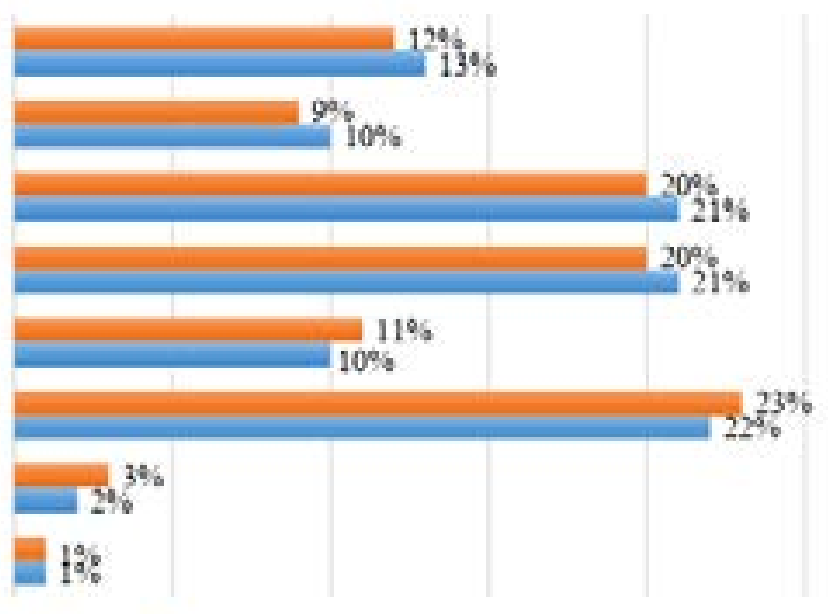

$2016=2012$

Fonte: TSE - Estatísticas.

Nesse último gráfico, observa-se que a maior parte do eleitorado porto-alegrense possui ensino fundamental incompleto e ensino médio completo ou incompleto, mais de $60 \%$ nos dois anos medidos. Além disso, a porcentagem de 
analfabetos ou pessoas que apenas leem e escrevem é muito pequena. As médias se mantêm relativamente estáveis para ambos os períodos comparativamente.

\section{A eleição municipal de 2008}

A eleição de 2008 em Porto Alegre foi caracterizada pela polarização no campo político de centro-esquerda. ${ }^{5}$ Além disso, a pulverização das identidades políticas da esquerda contribuiu para uma afirmação do desempenho do Partido do Movimento Democrático Brasileiro (PMDB) como dominante na disputa. Por fim, houve um "antipetismo" difuso que fez Fogaça não só atrair o apoio da centro-esquerda, mas também conquistar votos dentre os eleitores identificados com a direita (DIAS, NOLL, KRAUSE, 2011, p. 18).

Quadro 1 - Principais Candidatos à Prefeitura de Porto Alegre em 2008

\begin{tabular}{|c|c|c|}
\hline Candidato & Coligação & Partidos \\
\hline José Fogaça & Cidade Melhor - Futuro Melhor & PMDB/PDT/PTB/PSDC \\
\hline Luciana Genro & Sol e Verde & PSOL e PV \\
\hline Manuela d'Ávila & Porto Alegre é mais & PCdoB/PPS/PR/PTdoB/PMN/PSB/PTN \\
\hline Maria do Rosário & Frente Popular & PT/PRB/PSL/PTC \\
\hline
\end{tabular}

Fonte: As autoras.

A eleição de José Fogaça (PMDB) revela a relevância do voto retrospectivo para o eleitorado, como sugerem Dias, Noll e Krause (2011). A campanha sustentada pelo candidato baseava-se na avaliação positiva do seu governo anterior. Enquanto isso, a campanha da principal candidata oposicionista, Maria do Rosário (PT), tinha um posicionamento difuso e buscava exaustivamente - e sem sucesso - relacionar sua imagem à do então presidente da República, Luiz Inácio Lula da Silva (PT).

O sucesso da campanha de Fogaça baseada na avaliação retrospectiva resultou em sua eleição para segundo mandato como prefeito de Porto Alegre. Partido Comunista do Brasil (PCdoB) e Partido Socialismo e Liberdade (PSOL) coloca-

\footnotetext{
5 Para efeitos conceituais e de compreensão, esclarecemos que consideramos que PT, PCdoB, o PSOL, Partido Democrático Trabalhista (PDT) e Partido Socialista Brasileiro (PSB) estão à esquerda. Estabelecemos ainda candidatos fora da dicotomia PT/Anti-PT, aqueles que não são representantes do PT nem dos partidos de oposição explícita a esse, partindo da série histórica de disputas eleitorais no estado, sendo eles PMDB e PSDB e, mais recentemente, $\mathrm{PSOL}$.
} 
ram-se como opção em destaque para o eleitorado, o qual não se posicionou na dicotomia PT/PMDB, como pode ser visto na Tabela 2.

Tabela 2 - Votação para Prefeito em 2008 - $1^{\circ}$ Turno (principais partidos)

\begin{tabular}{|c|c|}
\hline Candidato & Votos (\%) \\
\hline José Fogaça (PMDB) & 43,85 \\
\hline Maria do Rosário (PT) & 22,73 \\
\hline Manuela d'Ávila (PCdoB) & 15,35 \\
\hline Luciana Genro (PSOL) & 9,22 \\
\hline
\end{tabular}

Fonte: TSE- Estatísticas.

Na Tabela 3, está o resultado do segundo turno do pleito:

Tabela 3 - Votação para Prefeito em 2008 - $2^{\circ}$ Turno

\begin{tabular}{|c|c|}
\hline Candidatos & Votos (\%) \\
\hline José Fogaça (PMDB) & 58,95 \\
\hline Maria do Rosário (PT) & 41,05 \\
\hline
\end{tabular}

Fonte: TSE- Estatísticas.

O sucesso da campanha de Fogaça

Desse modo, é importante destacar o papel central do discurso retrospectivo na campanha de Fogaça, sendo que esse candidato dedicou $60 \%$ de seu tempo com esse tipo de argumentação em 2008. ${ }^{6}$ Uma variável significativa de que esse posicionamento foi contundente é o fato de que, após o início do HGPE, houve importante mudança de opinião da população quanto à avaliação do governo.

6 Para observar os dados completos ver Dias, Noll e Krause (2011). 
Tabela 4 - Evolução da Avaliação do Governo Fogaça (\%)

\begin{tabular}{|c|c|c|c|}
\hline Avaliação & Antes do HGPE (24/07) & Início do HGPE (22/08) & 15 dias de HGPE (05/09) \\
\hline Ótimo / Bom & 29,5 & 34,1 & 47,1 \\
\hline Regular & 43 & 43 & 31,5 \\
\hline Ruim / Péssimo & 25 & 20,5 & 18,9 \\
\hline Não Sabe & 2,5 & 12,4 & 2,5 \\
\hline
\end{tabular}

Fonte: Instituto Datafolha, 2008.

Outro assunto relevante abordado por Fogaça foi o Orçamento Participativo (OP). O OP era reconhecidamente uma marca dos governos do PT em Porto Alegre, soba bandeira da participação direta e ampliação da democracia. Durante sua campanha, Fogaça buscou descolar o OP da imagem do PT, passando a ressignificá-lo como relacionado à uma conquista do povo e que permaneceria independente da gestão.

Os erros da oposição

Um dos principais erros dos partidos de oposição foi não estender suas propostas a uma área de interesse do eleitorado flutuante ao centro. Em geral, esse é um eleitorado mediano, que não tem grande interesse por política e não possui identificação partidária. Além disso, não investiram na busca do voto feminino, apesar das quatro principais candidatas oposicionistas serem mulheres. Outro deslize dessas campanhas foi não criticarem o candidato à reeleição (DIAS, NOLL E KRAUSE, 2011).

Fogaça criou uma imagem positiva acerca de seu mandato, e a oposição não desconstruiu isso. O PT, enquanto principal partido de oposição, não reivindicou as boas conquistas de seus governos até 2004, nem criticou a gestão do candidato da situação, deixando Fogaça buscar sozinho o eleitorado.

Rosário ficou restrita aos votos fiéis ao PT, mantendo seu isolamento à esquerda. Além disso, buscou insistentemente relacionar sua imagem à do então presidente Lula, o que não lhe garantiu sucesso. Manuela d'Ávila (PCdoB), no princípio, parecia ter a capacidade de realizar uma candidatura de boa representatividade, porém, como não tinha base forte, não resistiu à concorrência ao longo da campanha eleitoral. 
Características da campanha eleitoral de 2008

Um conjunto claro de fatores explica o resultado das eleições de 2008. O uso do discurso retrospectivo associado à avaliação positiva de seu governo foram contundentes para a vitória de Fogaça. O candidato do PMDB também conseguiu conquistar o eleitorado de classe média, que, essencialmente, concentra os votos do centro. Outro fator muito presente foi o uso do trabalhismo/associativismo nas campanhas, assunto muito bem aproveitado pelo candidato vencedor, que conseguir ainda dissociar o OP dos governos petistas.

Marenco (2009) argumenta que o eleitor porto-alegrense foi predominantemente pragmático em decidir seu voto baseado em uma avaliação retrospectiva do governo. A forma como os candidatos conseguiram utilizar as pesquisas de opinião no balizamento das estratégias de campanha teve papel central no sucesso ou insucesso de cada candidato (DIAS, NOLL E KRAUSE, 2011).

Com uma esquerda fragmentada e a deficiência dos partidos de direita em colocar-se como uma oposição significativa para o eleitorado antipetista, o PMDB atuou como um ímã que atraía tanto o centro-esquerda quando a direita.

\section{A eleição municipal de 2012}

A eleição de 2012 foi, de certo modo, uma continuação das eleições de 2008 no delineamento de um novo padrão de comportamento político eleitoral do município. É possível afirmar que houve a continuidade de vários traços importantes da primeira eleição e a conclusão de algumas tendências que já haviam sido apontadas em 2008.

Esse pleito foi, novamente, marcado por uma forte presença do discurso retrospectivo por parte do candidato da situação, de modo que José Fortunati, do Partido Democrático Trabalhista (PDT), venceu as eleições já no primeiro turno. Além disso, ocorreu uma alteração de protagonismo do partido oposicionista. Em 2008, o principal partido a fazer oposição ao candidato reeleito Fogaça (PMDB) foi o PT, já em 2012, o principal partido a fazer oposição ao candidato eleito Fortunati foi o PCdoB, novamente com d'Ávila. 
Quadro 2 - Principais Candidatos à Prefeitura de Porto Alegre em 2012

\begin{tabular}{|c|c|c|}
\hline Candidato & Coligação & Partidos \\
\hline José Fortunati & Por Amor a Porto Alegre & $\begin{array}{r}\text { PMDB/PDT/DEM/PMN } \\
\text { /PP/PPS/PRB/PTB/PTN }\end{array}$ \\
\hline Roberto Robaina & Aliança de Esquerda & PSOL e PCB \\
\hline Manuela d'Ávila & Juntos por Porto Alegre & PCdoB/PSD/PHS/PSB/PSC \\
\hline Adão Villaverde & Frente Popular-Governo de Verdade & $\begin{array}{r}\text { PT/PR/PV/PPL/PRTB/ } \\
\text { PTdoB/PTC }\end{array}$ \\
\hline Wambert di Lorenzo & Porto Alegre para Todos & PSDB/PRP \\
\hline
\end{tabular}

Fonte: As autoras.

Em 2012, o PT novamente arrecada apenas os votos do eleitorado fidelizado. A conquista do eleitorado de centro-esquerda se dá preponderantemente pelo PDT, com o PCdoB a obter algum sucesso na cooptação desse, mas a parcela era pequena. Além disso, Fortunati consegue agregar tanto os votos da direita - especialmente do eleitorado anti-PT/antiesquerda - quanto os votos do eleitorado que deixou de ter identificação partidária com o PT, visto que ele teve importante história no partido.

O principal avanço do PCdoB nas eleições em 2012 foi ocupar o lugar do PT enquanto principal partido oposicionista. No entanto, seu posicionamento durante a campanha foi bastante difuso, sem assumir uma temática definida. Buscou, essencialmente, associar ao seu governo uma ideia tecnocrática e a si mesmo uma imagem de liderança jovem junto ao governo federal.

Há um ponto fundamental em comum entre os três principais candidatos à prefeitura de Porto Alegre em 2012: Fortunati, d'Ávila e Villaverde compõem a base governista petista no plano nacional. Desse modo, todos procuraram relacionar sua imagem à do PT nacional - sem muito sucesso. A partir disso, cabe analisar o desempenho dos candidatos na eleição majoritária:

Tabela 5 - Votação para Prefeito em 2012 - $1^{\circ}$ Turno (principais partidos)

\begin{tabular}{|c|c|}
\hline Candidatos & \\
\hline José Fortunati (PDT) & 65,22 \\
\hline Manuela d'Ávila (PCdoB) & 17,76 \\
\hline Adão Villaverde (PT) & 9,64 \\
\hline
\end{tabular}

Fonte: TSE- Estatísticas. 
O gráfico acima mostra a grande superioridade do desempenho do PDT em relação a qualquer outro partido na disputa. Além disso, em comparação às eleições de 2008, há uma troca de posicionamento entre o PT - em queda - e o PCdoB, o segundo obtém quase o dobro de votos do primeiro. Evidenciando a diminuição considerável no papel desempenhado pelo PT. O PCdoB, por sua vez, manteve a mesma candidata nas duas eleições apostando em seu carisma pessoal e na sua relação com o governo federal.

O sucesso da campanha de Fortunati

A campanha eleitoral de Fortunati obteve um excelente desempenho, visto que o candidato não iniciou o período como favorito nas pesquisas de intenção de voto e acabou por ganhar as eleições no primeiro turno com uma votação esmagadora. De um modo geral, a campanha dele seguiu à risca a receita de seu predecessor Fogaça, em 2008.

Utilizou um discurso majoritariamente retrospectivo, aumentando a avaliação positiva de seu governo e passando a proposta de uma continuidade de algo que já está bom. Além disso, o candidato do PDT também busca utilizar o OP como uma conquista da população e como um compromisso de sua gestão, sem uma ligação direta com os governos PT.

É possível, então afirmar que a combinação de três fatores garantiu o sucesso da campanha de Fortunati em 2012. Primeiramente, o acirramento do isolamento do PT à esquerda. Além disso, a ineficiência da campanha da principal candidata oposicionista contribuiu para que o candidato do PDT ocupasse quase que sozinho a área mais fértil do eleitorado porto-alegrense, a centro-esquerda. Por fim, a reprodução da estratégia de campanha que já havia dado certo com Fogaça na eleição anterior.

Os erros da oposição

Os partidos de oposição mantiveram sua postura frágil ao não buscar atingir a área de interesse do eleitorado flutuante de centro. Outro erro repetido foi não criticarem o candidato à reeleição. Fortunati, assim como Fogaça, explorou a boa avaliação de seu mandato e os candidatos oposicionistas não se preocuparam em tentar problematizar os supostos benefícios do Governo Fortunati.

O PT deixou de ser o principal partido de oposição, abdicou das referências dos governos realizados pelo partido na capital e deixou, mais uma vez, que o 
candidato situacionista buscasse sozinho os votos retrospectivos. Todos os candidatos pretendendo sem sucesso relacionar sua imagem à do governo federal.

A principal candidata oposicionista, d'Ávila, iniciou o período de campanha como favorita entre os eleitores - conforme pesquisas de intenção de voto à época -, porém não apresentou uma campanha com um perfil definido ou uma coerência temática, procurando criar para si a imagem de uma líder jovem, tecnocrata, de forte atuação no governo federal.

\section{Características da campanha eleitoral de 2012}

As eleições de 2012 podem ser compreendidas a partir de um conjunto de fatores bastante similares aos observados nas eleições de 2008. A repetição do uso do discurso retrospectivo associado à avaliação positiva do seu governo continuam sendo aspectos essenciais na reeleição do candidato da situação. Além disso, o candidato do PDT conseguiu com sucesso herdar do PMDB o eleitorado de centro-esquerda. Fortunati também utilizou como instrumento de campanha o OP enquanto algo diretamente relacionado ao povo e com continuidade indiscutível, independentemente do partido governista.

É possível afirmar que as principais características dessa eleição foram a manutenção do eleitorado pelo voto retrospectivo, a continuidade do centro-esquerda como um espaço por excelência do eleitor porto-alegrense, o acentuado declínio do PT e a ascensão do PCdoB.

\section{A eleição municipal de 2016}

Se as eleições anteriores apresentam características semelhantes, o pleito de 2016 foi bastante diferenciado devido a uma série de fatores. Primeiramente, o resultado eleitoral apresentou uma quebra de paradigma com a vitória de um candidato de oposição. Para além disso, os argumentos e símbolos de apelo utilizados pelo candidato vitorioso foram distintos do que tradicionalmente vinha sendo valorizados pelo eleitorado nas urnas do estado e do município.

No que diz respeito ao cenário político, o ano de 2016 foi de muita conturbação e instabilidade, tendo como marco o impeachment da presidente eleita em 2014, Dilma Rousseff (PT), consequente polarização social em torno da questão e muita articulação e agitação entre os partidos. Por fim, outro ponto que sofreu transformação em relação às outras duas disputas analisadas aqui foi o maior papel da internet e das redes sociais. 
Nessa eleição, o desafio da situação era fazer mais uma vez um sucessor vitorioso seguindo a mesma fórmula da eleição anterior: apostar no vice-prefeito como candidato principal da chapa, visto que Fortunati havia assumido no lugar de Fogaça em 2010 e foi reeleito em 2012 - Fogaça renunciou à prefeitura para concorrer ao governo do Estado, conforme exige a legislação. A esse respeito, é importante notar que Melo não gozava do mesmo protagonismo político de seu antecessor.

Em contrapartida, a oposição tinha candidatos que, em sua maioria, possuíam perfis bem diferentes entre si. Marchezan (PSDB) e Maurício Dziedricki (PTB) podem ser caracterizados como quadros semelhantes: homens, jovens, com trajetória na vida pública, que propunham inovação e transformação da política. Luciana Genro (PSOL) foi a única personagem feminina, mas um perfil bem mais jovial que Raul Pont (PT), que representava de maneira mais forte o perfil mais tradicional do político gaúcho, ligado ao trabalhismo e a administração pública mais centralizadora.

Quadro 3 - Principais Candidatos à Prefeitura de Porto Alegre em 2016

\begin{tabular}{|c|c|c|}
\hline \multicolumn{1}{|c|}{ Candidato } & Coligação & Partidos \\
\hline Luciana Genro & É a Vez da Mudança & PSOL, PCB e PPL \\
\hline Maurício Dziedricki & Novas Ideias & PTB, PR, PSC, PTdoB, PRP e SD \\
\hline Nelson Marchezan Júnior & Porto Alegre pra frente & PSDB, PP, PMB, PTC e PV \\
\hline Raul Jorge Pont & Porto Alegre Democrática & PT e PCdoB \\
\hline Sebastião de Araújo Melo & Abraçando Porto Alegre & $\begin{array}{c}\text { PMDB, PDT, PSD, PSB, DEM, } \\
\text { PRB, PPS, PROS, PTN, REDE, } \\
\end{array}$ \\
\hline
\end{tabular}

Fonte: As autoras.

A partir dessas informações e considerações, cabe apresentar alguns dados acerca da estrutura e concepção que os candidatos tinham do uso das redes sociais durante essa campanha. Veja, antes, os quadros com os endereços eletrônicos dos candidatos: 
Quadro 4 - Links das Campanhas dos Candidatos em 2016

\begin{tabular}{|c|c|}
\hline \multicolumn{2}{|r|}{ Luciana Genro } \\
\hline Site & https://lucianagenro.com.br/ \\
\hline Facebook & https://www.facebook.com/LucianaGenroPSOL/?fref=ts \\
\hline Twitter & https://twitter.com/lucianagenro/ \\
\hline Instagram & https://www.instagram.com/lucianagenro/ \\
\hline YouTube & https://www.youtube.com/user/LucianaGenroPSOL/ \\
\hline \multicolumn{2}{|r|}{ Maurício Dziedricki } \\
\hline Site & http://mauricio14.com.br/ (offline) \\
\hline Facebook & https://www.facebook.com/MauricioPTBRS/?fref=ts \\
\hline Twitter & https://twitter.com/mauricioptbrs \\
\hline Instagram & https://www.instagram.com/mauricioptbrs/ \\
\hline YouTube & https://www.youtube.com/channel/UCbDXyFVXSs5j\%E2\%80\%93tJ8GDy9Z7w (offline) \\
\hline \multicolumn{2}{|r|}{ Nelson Marchezan } \\
\hline Site & http://marchezanprefeito.com.br/ (offline) \\
\hline Facebook & https://www.facebook.com/nelsonmarchezan/ \\
\hline Twitter & https://twitter.com/marchezan \\
\hline Instagram & https://www.instagram.com/marchezanjr/ \\
\hline YouTube & https://www.youtube.com/channel/UC3y7JVQqDBQkDn3zN\%E2\%80\%936X53A (offline) \\
\hline \multicolumn{2}{|r|}{ Raul Pont } \\
\hline Site & http://raulpont.com.br/ (offline) \\
\hline Facebook & https://www.facebook.com/raulpont/?fref=ts \\
\hline Twitter & https://twitter.com/raulpont \\
\hline Instagram & https://www.instagram.com/raulpont/ \\
\hline YouTube & https://www.youtube.com/channel/UCGf48WQdqzE4hm6gzbytsBA \\
\hline
\end{tabular}

\begin{tabular}{|c|c|}
\hline \multicolumn{1}{|c|}{ Sebastião Melo } \\
\hline Facebook & $\underline{\text { http://melor5.com.br/(offline) }}$ \\
\hline Twitter & $\underline{\text { https://www.facebook.com/MeloSebastiao/?fref=ts }}$ \\
\hline Instagram & $\underline{\text { https://twitter.com/SebastiaoMelo }}$ \\
\hline YouTube & $\underline{\text { https://www.instagram.com/melosebastiaopoa/ }}$ \\
\hline
\end{tabular}

Fonte: As autoras. 
Quadro 5 - Uso das Redes Sociais (principais candidatos)

\begin{tabular}{|c|c|c|c|}
\hline & Luciana Genro & Maurício Dziedricki & Raul Pont \\
\hline Facebook & 484.489 & $5,2 \mathrm{mil}$ & $16,5 \mathrm{mil}$ \\
\hline Twitter & $200 \mathrm{mil}$ & $1,7 \mathrm{mil}$ & $8,2 \mathrm{mil}$ \\
\hline Instagram & $47 \mathrm{mil}$ & $2,5 \mathrm{mil}$ & $92 \mathrm{mil}$ \\
\hline YouTube & $10 \mathrm{mil}$ & 25 & 55 \\
\hline Estrutura & $\begin{array}{l}\text { Seis pessoas fixas e um } \\
\text { grupo de militantes } \\
\text { apoiando o trabalho }\end{array}$ & $\begin{array}{l}\text { Sete pessoas entre } \\
\text { jornalistas e publicitários }\end{array}$ & $\begin{array}{l}\text { Três social medias e rede de } \\
\text { apoiadores da militância/ } \\
\text { partido }\end{array}$ \\
\hline $\begin{array}{l}\text { Conteúdo } \\
\text { no } \\
\text { Facebook }\end{array}$ & $\begin{array}{c}\text { Notícias e fotos sobre atos } \\
\text { da candidata e cards com } \\
\text { propostas }\end{array}$ & $\begin{array}{l}\text { Cards sobre a agenda } \\
\text { e vídeos de pessoas } \\
\text { da comunidade ou } \\
\text { candidatos apoiando, } \\
\text { reprodução de trechos } \\
\text { dos programas da TV } \\
\text { e fotos dos atos de } \\
\text { campanha. }\end{array}$ & $\begin{array}{l}\text { Reaproveitamento de } \\
\text { conteúdos produzidos para } \\
\text { a televisão e o rádio, além do } \\
\text { que é gerado pela agenda }\end{array}$ \\
\hline Estratégia & $\begin{array}{l}\text { Utilizar o meio como uma } \\
\text { forma desenvolver suas } \\
\text { ideias, visto que contavam } \\
\text { com pouco tempo de } \\
\text { televisão, e oferecer } \\
\text { informações mais diretas ao } \\
\text { eleitorado. }\end{array}$ & $\begin{array}{c}\text { Utilizar a mesma } \\
\text { linguagem das ruas e uma } \\
\text { utilização bem pessoal } \\
\text { das redes. }\end{array}$ & $\begin{array}{c}\text { Explorar a informação em } \\
\text { tempo real, a interatividade } \\
\text { e feedbacks. Possibilidade de } \\
\text { desenvolver vínculos mais } \\
\text { duradouros. }\end{array}$ \\
\hline
\end{tabular}




\begin{tabular}{|c|c|c|}
\hline & Nelson Marchezan & Sebastião Melo \\
\hline Facebook & $93 \mathrm{mil}$ & $16 \mathrm{mil}$ \\
\hline Twitter & $8,7 \mathrm{mil}$ & $4,5 \mathrm{mil}$ \\
\hline Instagram & $2,4 \mathrm{mil}$ & 600 \\
\hline YouTube & 32 & 28 \\
\hline Estrutura & $\begin{array}{c}\text { Cinco pessoas cuidam das redes sociais } \\
\text { do candidato, com integrantes de } \\
\text { diferentes áreas, como economia e } \\
\text { publicidade }\end{array}$ & $\begin{array}{c}10 \text { pessoas, entre jornalistas, designers, } \\
\text { publicitário }\end{array}$ \\
\hline $\begin{array}{l}\text { Conteúdo } \\
\text { no Facebook }\end{array}$ & $\begin{array}{c}\text { Cards com frases, além de divulgar os } \\
\text { programas de TV e rádio. }\end{array}$ & $\begin{array}{l}\text { Programas de TV publicados antes de irem } \\
\text { ao ar. Vídeos abordando a agenda. Cards } \\
\text { que apresentam os compromissos do } \\
\text { candidato no dia. Fotos da campanha. }\end{array}$ \\
\hline Estratégia & $\begin{array}{l}\text { Divulgação das propostas e destaque a } \\
\text { tudo o que o Marchezan já fez. Uso de } \\
\text { gifs, vídeos e cards. Mostrar coerência, } \\
\text { identidade e reputação anteriores à } \\
\text { campanha. }\end{array}$ & $\begin{array}{l}\text { Uso de hashtag, programas de computador } \\
\text { e celular voltados para acessibilidade. }\end{array}$ \\
\hline
\end{tabular}

Fonte: Site da Gaúcha ZH, ClicRBS.

Com base no quadro, é possível observar diferenças entre o uso e a representatividade dos principais candidatos na internet. Genro é a candidata que mais possui base de apoio nas redes sociais e utiliza as mesmas de forma mais ideológica com participação e estratégias marcadas pela atuação da militância.

Dziedricki opta por estrutura e estratégia mais profissionais e personalizadas e é o candidato com menor alcance nesse meio. Pont possui relativa expressividade nas redes sociais e, assim como Genro, atua de forma mais partidária e ideológica em suas postagens.

Marchezan também opta por uma estratégia de comunicação mais profissionalizada e pessoal nas redes sociais, com conteúdo mais objetivo e direto e é um dos candidatos com maior popularidade nos diferentes veículos. Melo também possui uma estrutura bastante técnica, mas opta por um conteúdo mais geral, relacionado à agenda do candidato e dependente da campanha na televisão.

Com relação aos principais instrumentos de discurso dos candidatos e sua atuação na propaganda eleitoral gratuita, Melo teve como principal temática de campanha a defesa das gestões anteriores com a ideia de manter tudo que já vinha 
sendo feito de bom pela cidade e transformar o que ainda precisava ser feito, ou seja, manteve o discurso básico de um candidato de situação, especialmente por não possuir protagonismo político ou apadrinhamento político de expressividade.

Genro e Pont não procuraram desconstruir a gestão da situação de maneira significativa, optando por manter um direcionamento semelhante ao da oposição nas eleições de 2008 e 2012, colocando-se, assim, no espectro definido por Manin (1995) e Norris (2000) como a segunda etapa da trajetória democrática, isto é, marcada pelo apelo à ideologia, à militância e ao associativismo.

Dziedricki adotou uma postura de não embate com os demais candidatos, sua campanha baseou-se mais em torná-lo uma figura conhecida pelos eleitores, reforçando suas características pessoais e ideias de gestão e deixando de lado os aspectos políticos, partidários ou ideológicos de sua candidatura. Marchezan, por sua vez, construiu uma campanha bastante combativa em relação à gestão de Melo e seus antecessores. Além disso, optou por um descolamento das estruturas ideológicas e partidárias em detrimento da valorização de seu perfil inovador, propositivo e integrado às formas modernas de gestão pública.

No primeiro turno, Marchezan conquistou o primeiro lugar, resultado que sugere que uma postura mais combativa em relação à situação, somada a transformações na conjuntura social e política do pleito, pode ter resultado em uma mudança no cenário eleitoral porto-alegrense.

Tabela 6 - Votação para Prefeito em 2016 - $1^{\circ}$ Turno (principais partidos)

\begin{tabular}{|c|c|}
\hline Candidatos & Votos (\%) \\
\hline Nelson Marchezan (PSDB) & 29,84 \\
\hline Sebastião Melo (PMDB) & 25,93 \\
\hline Raul Pont (PT) & 16,37 \\
\hline Maurício Dziedricki (PTB) & 13,68 \\
\hline Luciana Genro (PSOL) & 12.06 \\
\hline
\end{tabular}

Fonte: TSE - Estatísticas.

O segundo turno das eleições foi marcado por uma disputa baseada no confronto entre as duas partes envolvidas. Marchezan procurou desconstruir e criticar à exaustão a administração dos governos anteriores e, especialmente, a versão dos fatos trazida 
por Melo em sua propaganda eleitoral. Com frequência, o candidato oposicionista questionava "onde ficava a Porto Alegre das propagandas de Sebastião Melo".

Ao candidato de situação, por sua vez, restou defender a gestão em que foi vice-prefeito e tentar comprovar constantemente as informações que trazia em seu tempo de televisão e eram contestadas por seu oponente. Desta forma, quem acabou ditando o ritmo, a temática e o tom da propaganda eleitoral do segundo turno foi Marchezan.

As eleições de 2016 representam, assim, uma mudança no paradigma político eleitoral do município, substituindo a lógica de conservação da ordem e de um discurso político trabalhista e associativista por uma proposta mais tecnocrática, descolada de quesitos partidários e ideológicos. Consequentemente, há a sugestão de que o eleitorado porto-alegrense tem atravessado, a partir das mudanças nas características próprias desse pleito, da segunda para a terceira etapa da democracia conforme definidas por Manin (1995) e Norris (2000).

Tabela 7 - Votação para Prefeito em $2016-2^{\circ}$ Turno

\begin{tabular}{|c|c|}
\hline Candidatos & Votos (\%) \\
\hline Nelson Marchezan (PSDB) & 60,5 \\
\hline Sebastião Melo (PMDB) & 39,5 \\
\hline
\end{tabular}

Fonte: TSE - Estatísticas.

\section{O sucesso da campanha de Marchezan}

O principal diferencial da campanha Marchezan em relação às que buscavam romper com a continuidade da situação nas eleições anteriores, foi sua postura crítica e combativa em relação às administrações passadas. A estratégia de comunicação política construída por ele e pela sua equipe foi muito oportuna na medida em que propôs novos paradigmas e se apropriou das ferramentas mais inovadoras em um momento de instabilidade e desconstrução de esquemas tradicionais, políticos e sociais.

Conseguiu mesclar uma imagem pessoal de experiência política com inovação e mudança, o que foi muito trabalhado no conteúdo e forma de sua propaganda política: se, por um lado, buscava apresentar seu trabalho e conquistas enquanto deputado federal, por outro, aparecia sempre em movimento pela cidade - trazendo a ideia de transformação - ao mesmo tempo que falava sobre a situação do município e suas propostas. 
O segundo turno foi pautado pelas críticas à administração de Fortunati e Melo e pelas temáticas que lançava em sua propaganda eleitoral gratuita. $O$ candidato de situação, Melo, apenas reagiu e respondeu aos seus questionamentos e argumentos.

Por fim, conforme já foi salientado anteriormente, as eleições de 2016 foram marcadas, também, pela presença dos candidatos na internet, sendo a equipe de Marchezan a mais bem-sucedida em adesão à imagem do candidato. Abaixo, temos uma nuvem de palavras com os termos mais frequentes na sua página do Facebook:

Nuvem de Palavras 1 - Termos mais frequentes - Facebook de Nelson Marchezan (PSDB)

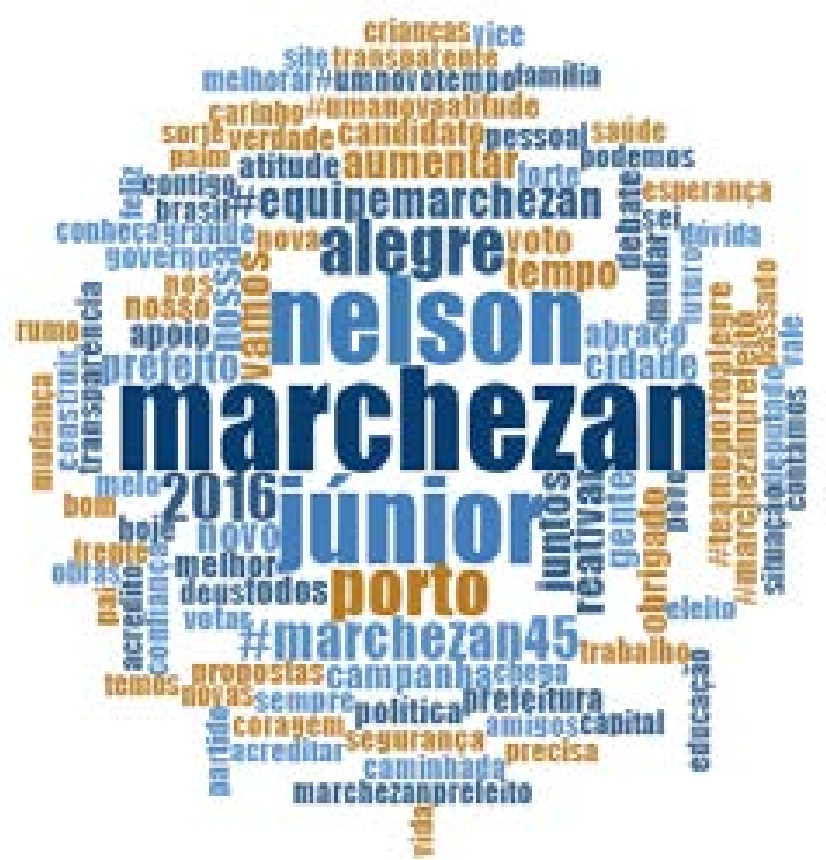

Fonte: As autoras. Uso do software NVivo 11 sobre todas as postagens na página oficial no Facebook de Nelson Marchezan Júnior no período de campanha eleitoral (16/08/2016 a 28/10/2016).

De um modo geral, os termos encontrados com maior frequência - rumo, futuro, mudança, transparência, esperança, acreditar, uma nova atitude, um novo tempo, novo, novas, entre outros - reforçam a ideia de que o candidato era um quadro tecnocrático capaz de promover transformações políticas e de gestão. Além disso, fica clara a crítica a Melo no uso recorrente das seguintes palavras: situação, Melo, crítica, passado.

Aparecem também palavras que reforçam o perfil de Marchezan enquanto um político experiente, porém identificado com a modernização, como: deputado, coragem, atitude, forte. Por fim, temos o básico de uma comunicação política de campanha: promessas com os termos segurança, saúde, educação, propostas e obras. 
Dessa forma, fica clara a harmonia dos argumentos, postura e temáticas utilizadas pelo candidato em qualquer um dos meios analisados. É possível dizer que em qualquer aspecto que se olhe sua campanha, vemos um caráter completo e coerente ao tratar de todos os temas e ao utilizar todos os possíveis instrumentos de comunicação de forma estratégica.

Os erros da oposição

Para fins analíticos, é preciso avaliar separadamente as estratégias de comunicação política de campanha do candidato de situação, Melo, e dos demais candidatos que buscavam romper com a continuidade, mas não obtiveram sucesso.

Genro, Pont e Dziedricki optaram por uma campanha nos mesmos moldes da oposição nas eleições de 2008 e 2012: evitar a crítica à gestão em vigência. Usando diferentes formas, Genro e Pont, mais pelo viés ideológico/partidário, e Dziedricki, com uma identidade mais pessoal e tecnocrática. Esses candidatos estiveram mais preocupados em apresentar a si mesmos e as suas propostas enquanto uma opção válida, sem desconstruir a alternativa vigente ou preponderante no momento da campanha.

Melo, por sua vez, tinha como meta a manutenção de seu grupo político no poder a partir da defesa da gestão de Fortunati, da qual foi vice. O candidato partiu de uma conjuntura privilegiada, dada a tradição política de perpetuação vigente no município até então, contudo não gozava do protagonismo e carisma dos seus antecessores. Tampouco obteve sucesso em sua tentativa de se tornar uma figura mais popular - com vistas a essa estratégia, algumas peças de propaganda o apresentavam como Tião ou Bastião. Durante o segundo turno, foi envolvido pela argumentação e posicionamento propositivo de Marchezan e acabou por fazer uma campanha reativa e enfatizando os argumentos do opositor Marchezan ao repeti-las em suas defesas. Na nuvem de palavras a seguir, apresentamos os termos mais frequentes na página do Facebook do candidato: 
Nuvem de Palavras 2 - Termos mais frequentes - Facebook de Sebastião Melo (PMDB)

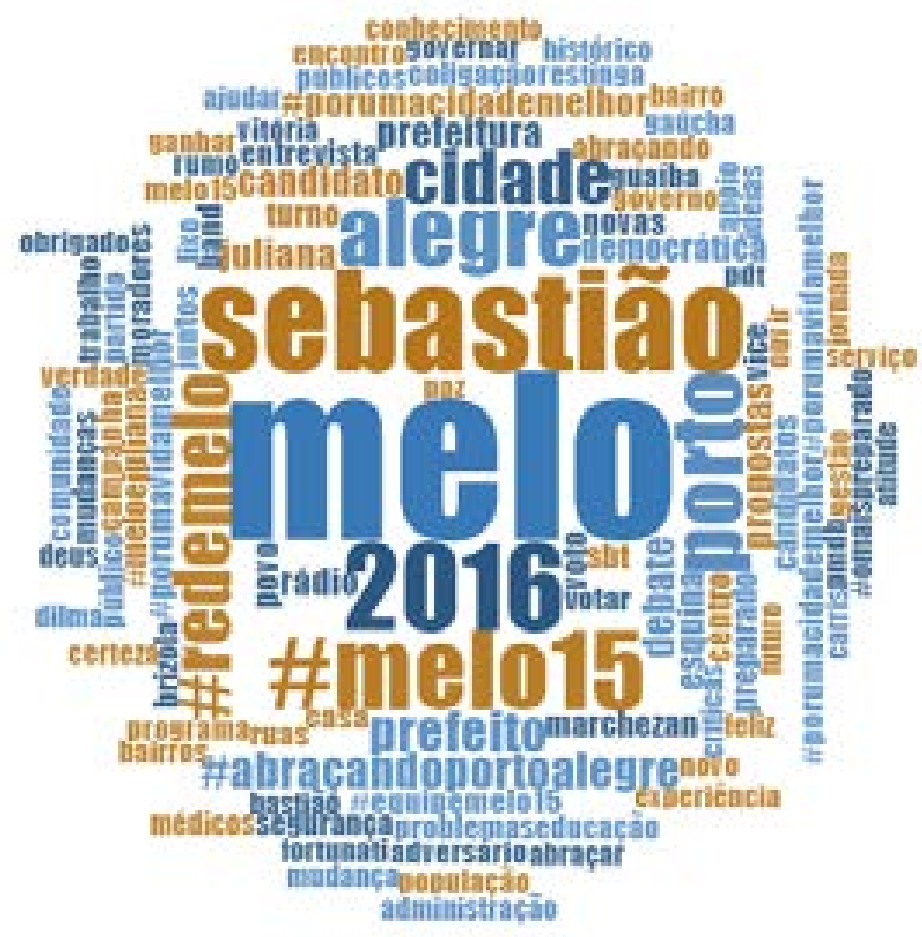

Fonte: As autoras. Uso do software NVivo 11 sobre todas as postagens na página oficial no Facebook de Sebastião Melo no período de campanha eleitoral (16/08/2016 a 28/10/2016).

A nuvem de palavras mostra que o principal conteúdo publicado na rede social de Melo foi sua agenda e seus principais compromissos e atos de campanha, expostos por meio das palavras SBT, Band, Guaíba, Gaúcha, moradores, bairro, rádio, debate, ruas, programa, esquina, entrevista. Outra categoria de termo bastante frequente diz respeito a fatores políticos como siglas de partidos, Rousseff e Fortunati, o que deixa claro o quanto Melo, diferentemente de Marchezan, tinha sua campanha bastante ligada a critérios associativistas e partidários. Aparecem ainda termos básicos de campanha eleitoral - educação, médicos, gestão, histórico, vice, educação, administração -, e alguns termos de atributos pessoais, como experiência, conhecimento, Bastião e preparado.

De um modo geral, a comunicação política de Melo na internet reflete as estratégias já descritas anteriormente e acabaram por não contribuir na reversão da paralisia estratégica em que sua campanha estacionou a partir dos ataques e argumentos de Marchezan. 


\section{Uma comparação}

O Quadro 6 traz um resumo e a comparação das principais características das estratégias de comunicação eleitoral dos vencedores nos três pleitos em Porto Alegre.

Quadro 6 - Comparação das eleições de 2008, 2012 e 2016

\begin{tabular}{|c|c|c|c|}
\hline & $\begin{array}{l}\text { José Fogaça } \\
\qquad(2008)\end{array}$ & José Fortunati (2012) & $\begin{array}{l}\text { Nelson Marchezan } \\
\text { (2016) }\end{array}$ \\
\hline Votação (\%) & $\begin{array}{l}43,85\left(1^{\circ} \text { turno }\right) \\
58,95\left(2^{\circ} \text { turno }\right)\end{array}$ & 65,21 ( $1^{\circ}$ turno) & $\begin{array}{l}29,84\left(1^{\circ} \text { turno }\right) \\
60,50\left(2^{\circ} \text { turno }\right)\end{array}$ \\
\hline Temas mais citados & $\begin{array}{c}\text { Administração da cidade } \\
\text { OP ligado às bandeiras } \\
\text { do trabalhismo/ } \\
\text { associativismo }\end{array}$ & $\begin{array}{l}\text { Administração da } \\
\text { cidade } \\
\text { OP }\end{array}$ & $\begin{array}{c}\text { Experiência política } \\
\text { Propostas de inovação e } \\
\text { mudança }\end{array}$ \\
\hline Abordagem & $\begin{array}{l}\text { Auto avaliação } \\
\text { retrospectiva positiva }\end{array}$ & $\begin{array}{l}\text { Auto avaliação } \\
\text { retrospectiva positiva }\end{array}$ & $\begin{array}{c}\text { Avaliação retrospectiva } \\
\text { crítica e negativa da gestão } \\
\text { anterior } \\
\text { Imagem de mudança e } \\
\text { movimento }\end{array}$ \\
\hline $\begin{array}{l}\text { Principais meios } \\
\text { utilizados }\end{array}$ & $\begin{array}{l}\text { Televisão, rádio e } \\
\text { campanha de rua }\end{array}$ & $\begin{array}{l}\text { Televisão, rádio e } \\
\text { campanha de rua }\end{array}$ & $\begin{array}{l}\text { Televisão, internet e mídias } \\
\text { sociais, campanha de rua }\end{array}$ \\
\hline
\end{tabular}

Fonte: As autoras.

Como comentado anteriormente, os pleitos de 2008 e 2012 foram marcados por algumas semelhanças. Fogaça e Fortunati ainda focaram na autoavaliação retrospectiva positiva, buscando convergência com essa característica histórica do comportamento do eleitor do município. Marchezan, no entanto, em 2016, assume uma abordagem de avaliação retrospectiva crítica e negativa da gestão anterior, projetando sua imagem como de mudança e movimento.

Uma alteração, já significativa, ocorre entre os temas dois primeiros pleitos - mesmo que ambos tenham destacado a administração da cidade e o OP: em 2008, a estratégia mantém-se ligada às bandeiras do trabalhismo e associativismo, outro tema caro ao porto-alegrense ao longo da história, no entanto, em 2012, Fortunati abandona essa bandeira. Em 2016, há inflexão para o destaque à experiência política e às propostas de inovação.

No que se refere ao uso da mídia, as comunicações de Fogaça e Fortunati ainda foram feitas principalmente pelos meios de massa - televisão e rádio - e na tradicional campanha de rua. A campanha de Marchezan entrou na era digital da internet e das redes sociais, retirando importância ao rádio. 


\section{Conclusão}

Na primeira parte deste estudo, buscamos analisar as principais características do eleitorado porto-alegrense. Em termos demográficos, trata-se de um público urbanizado, equilibrado entre homens e mulheres, de escolaridade média e, em sua maioria, em idade economicamente ativa. Ao longo de sua história, tem apresentado um posicionamento preponderantemente de centro-esquerda e com valorização do discurso retrospectivo associado à uma avaliação positiva de governo e da temática do trabalhismo/associativismo.

Ao analisar as três eleições neste estudo, podemos identificar que esse cenário se repete até as eleições de 2012. Os pleitos de 2008 e 2012 foram bastante semelhantes entre si. Ambos seguiram um mesmo roteiro, apresentaram um mesmo padrão de fatores e comportamentos que os definiram. Contudo, ao olhar detalhadamente as eleições de 2016 , não chegaremos à mesma conclusão.

Em 2016, o que se observa é uma mudança bastante radical da fórmula histórica, fruto de uma situação conjuntural adversa ou ainda resultado de uma mudança de postura da oposição e da substituição do modelo de participação democrática partidário, associativista e ideológico, por um modelo mais personalista, apolítico e pragmático. Cabem novas investigações no futuro, após novos pleitos eleitorais, para considerar se esse novo modelo se manterá ou ficará restrito a uma conjuntura específica.

A partir da avaliação da literatura e do uso de cada ferramenta de comunicação por cada candidato, é possível concluir que há alguns instrumentos aos quais os candidatos às eleições majoritárias no município devem dar especial atenção. Um fator importante é a conquista do eleitorado de classe média, que concentra os votos do eixo centro e tem mostrado predisposição a aderir a campanhas mais simples, objetivas, diretas e técnicas - com um esvaziamento do conteúdo político, partidário e ideológico. O HGPE também se mostra como algo que tem influência sobre o voto em Porto Alegre. Por fim, as redes sociais foram uma ferramenta muito poderosa quando utilizada de forma eficiente no reforço e manutenção do eleitor mais posicionado e, também, na conquista de eleitores indecisos ou flutuantes.

Em termos de padrões de sucesso e fracasso na comunicação política eleitoral, é possível destacar quatro pontos. Primeiramente, o discurso retrospectivo tem forte apelo na cidade, a garantir de antemão que o candidato de situação inicie a disputa em uma posição privilegiada em relação aos demais.

Além disso, posturas de oposição que mantém um posicionamento difuso e não crítico ou combativo em relação à gestão em andamento e ao candidato 
de situação tendem a não conseguir estabelecer uma candidatura competitiva. A tentativa de associação com padrinhos políticos - em especial do cenário nacional - também não obteve sucesso em nenhuma das tentativas feitas.

Outro fator importante é a ruptura da continuidade de um mesmo grupo político no poder a partir de um candidato de oposição que se propôs a problematizar, criticar e discutir a concepção de cidade descrita pelos candidatos de situação, estratégia tão bem-sucedida que acabou por pautar a disputa de segundo turno na capital gaúcha em 2016.

Por fim, é preciso destacarmos o que parece ser uma quebra de paradigma no perfil de adesão do eleitorado porto-alegrense, definido pela substituição do apelo das estruturas ideológicas, partidárias e associativistas pela preferência por quadros tecnocráticos, esvaziados de conteúdo político e dotado de atributos pessoais e pelo uso das novas mídias.

\section{REFERÊNCIAS}

BAQUERO, Marcello; PRÁ, Jussara Reis. Matriz histórico-estrutural da cultura política no Rio Grande Sul e padrões de participação política. Cadernos de Ciência Política, Série Pré-Edições, n. 3. Porto Alegre: Universidade/UFRGS, 1995. https://doi.org/10.22533/ at.ed.2301828122

CANAVILHAS, João. A comunicação política na era da internet. VIII CONGRESSO LUSOCOM. Labcom, 2009.

CASTELLS, Manuel. La era de la información. Madrid: Alianza Editorial, 1996. v. I. La sociedad en red.

COSTA, Ricardo. A Comunicação na Campanha Política. Aurora Revista de Arte, Mídia e Política, São Paulo, v. 6, n. 16, p. 65-94, fev.-maio 2013.

DIAS, M. R.; NOLL, M. I. S; KRAUSE, Silvana. O eleitor portoalegrense: voto retrospectivo, identidade partidária e estabilidade política. In: LAVAREDA, Antonio; TELLES, Helcimara (org.). Como o eleitor escolhe seu prefeito. Rio de Janeiro: Editora FGV, 2011. p. 229-262.

FEE. Fundação de Economia e Estatística. PIB dos municípios do RS em 2015: municípios industriais foram os mais afetados em ano de crise. Disponível em: https://www.fee. rs.gov.br/indicadores/pib-rs/municipal/destaques/. Acesso em: 18 dez. 2018. https:// doi.org/10.21115/jbes.v8.n2.p108-117

FERREIRA, Suzana Andrade. A internet como meio de comunicação política e construção de imagem no Brasil democrático. IV ENCONTRO DA ASSOCIAÇÃO BRASILEIRA DE PESQUISADORES EM COMUNICAÇÃO POLÍTICA (COMPOLÍTICA). Universidade Federal do Rio de Janeiro, 2011. https://doi.org/10.1590/1807-01912016223524 
FIGUEIREDO, Ney Lima. Jogando para ganhar. Marketing político: verdade e mito. Geração Editorial, 1994.

GAÚCHA ZH. Eleições 2016: Como os principais candidatos de Porto Alegre usam as redes sociais em campanha. Zero Hora. 21 set. 2016. Disponível em: https://gauchazh. clicrbs.com.br/politica/eleicoes-2016/noticia/2016/og/como-os-principais-candidatos-de-porto-alegre-usam-as-redes-sociais-em-campanha-7513903.html. Acesso em: 4 fev. 2018. https://doi.org/10.5216/sec.v15i1.20670

GIDDENS, Anthony. The Consequences of Modernity. Cambridge: Polity Press, 1990. HOWARD, Philip N. New Media Campaigns and the Managed Citizens. Cambridge: University Press, 2006.

KERBEL, Matthew Robert. Edited for television: CNN, ABC and American Presidential elections. Boulder: Westview Press, 1998.

LLOYD, Jenny. Square peg, round hole? Can marketing-based concepts such as 'product' and the 'marketing-mix' have a useful role in political arena? In: W. WYMER JR.; J. LEES-MARSHMENT (ed.). Current Issues in Political Marketing. Binghamton: The Haworth Press, 2005. https://doi.org/10.1300/j054V14no1_03

MANIN, Bernard. As metamorfoses do governo representativo. Revista Brasileira de Ciências Sociais, n. 29, p. 5-34, 1995.

MARENCO, André. Voto em dois tempos: Notas sobre as eleições 2008 em Porto Alegre. In: BAQUERO, Marcello; CREMONESE, Dejalma (org.). Eleições Municipais 2008: Uma análise do Comportamento Eleitoral Brasileiro. ljuí: Ed. Ijuí, 2009. p. 67-81. https://doi. org/10.5585/rdb.v2i2.86

NORRIS, Pippa. Virtuous Circle - Political Communications in Postindustrial Societies. Cambridge: University Press, 2000. https://doi.org/10.1093/ijpor/13.4.442

PASSOS, Manoel; NOLL, Maria Isabel. Eleições Municipais em Porto Alegre (1947-1992). Porto Alegre, 1996.

PORTO ALEGRE. Prefeitura Municipal. Anuário Estatístico - 2016. Porto Alegre: Prefeitura Municipal de Porto Alegre/Secretaria Municipal de Planejamento Estratégico e Orçamento/ Gerência de Monitoramento de Resultados, 2016. Disponível em: http://lproweb.procempa.com.br/pmpa/prefpoa/smpeo/usu doc/anuario estatistico 2016 31-10.pdf. Acesso em: 18 dez. 2018. https://doi.org/10.5700/rege328

ESPÍRITO SANTO, Paula do; FIGUEIRAS, Rita. Comunicação eleitoral. In: CORREIA, João Carlos; FERREIRA, Gil Baptista; ESPÍRITO SANTO, Paula do (org.). Conceitos de Comunicação Política. LabCom Books, 2010. 
SERRANO, Estrela. Spin doctoring e profissionalização da comunicação política. In: CORREIA, João Carlos; FERREIRA, Gil Baptista; SANTO, Paula do Espírito (org.). Conceitos de Comunicação Política. Covilhã, 2010. p. 91-98.

SWANSON, David L. El campo de la comunicación política: la democracia en los médio. In: MUNÕZ-ALONSO, A.; ROSPIR, J. L. Comunicación Política. Madrid: Ed. Universitas, 1995. https://doi.org/10.2307/j.ctvng6f5x.7

TRINDADE, Helgio. Padrões e tendências do comportamento eleitoral no Rio Grande do Sul (1950/1974). In: CARDOSO, Fernando Henrique; LAMOUNIER, Bolívar (org.). Os Partidos e as Eleições no Brasil. Rio de Janeiro: Paz e Terra, 1975. https://doi.or$\mathrm{g} / 10.1590 / 1806-93472016 \mathrm{v} 36 \mathrm{n} 73-016$

TRINDADE, Helgio; NOLL, M. I. S. Rio Grande da América do Sul - Partidos e Eleições (1823-1990). Porto Alegre: Ed. da Universidade/UFRGS/Sulina, 1991. https://doi. org/10.21041/conpat2019/v2pat222

TSE. Tribunal Superior Eleitoral. Brasil. Disponível em: http://www.tse.jus.br/. Acesso em: 18 dez. 2018.

\section{Dados da autora:}

\section{Carla Mendonça - e-mail: cetiene@gmail.com}

Pesquisadora do Doutoramento em Ciências da Comunicação e do Laboratório de Ciências da Comunicação do Centro de Investigação e Estudos de Sociologia (CIES-IUL) do ISCTE - Instituto Universitário de Lisboa, Portugal. Doutora desde 2013 em Ciências Sociais, Especialista em Estudos Comparados sobre as Américas, pelo Centro de Pesquisa e Pós-Graduação sobre as Américas (Ceppac) do Instituto de Ciências Sociais (ICS) da Universidade de Brasília (UnB), Brasil, com bolsa da Capes/MEC. Especialização em Relações Internacionais pelo Instituto de Relações Internacionais (Irel) da UnB em 2008. Graduada pela Faculdade de Biblioteconomia e Comunicação Social (Fabico) com ênfase em Jornalismo pela UFRGS, Brasil, em 1998.

\section{Endereço da autora:}

ISCTE-Instituto Universitário de Lisboa - Av. das Forças Armadas, 1649-02, Bauru (SP) - Portugal 


\section{Dados da autora:}

Jéssica Duarte - e-mail: eh.sduarte@gmail.com

Doutoranda em Ciência Política pelo Programa de Pós-Graduação em Ciência Política da Universidade Federal do Rio Grande do Sul e mestre em Ciência Política pelo mesmo programa. Graduada bacharel em Ciências Sociais pela UFRGS. Pesquisadora no Grupo de Pesquisa em Cultura Política do PPGPOL UFRGS e colaboradora da equipe do World Value Survey Brasil. Além disso, participa das atividades do Núcleo de Pesquisa sobre a América Latina (NUPESAL). Foi colaboradora em grupos de pesquisa no Núcleo de Pesquisa e Documentação da Política Rio-Grandense (NUPERGS), sob a orientação da professora Doutora Maria Izabel Saraiva Noll. Dedicando-se, atualmente, a pesquisas na área de Cidadania e Qualidade Democrática.

\section{Endereço da autora:}

Universidade Federal do Rio Grande do Sul

Programa de Pós-Graduação em Ciência Política - Av. Bento Gonçalves, 9500

- Prédio 43322 (IFCH)/Sala 205, Bairro Agronomia - Porto Alegre (RS), Brasil 